\section{A construção social de sentidos \\ e o fenômeno da recepção: em questão o papel dos realizadores}

\section{RESUMO}

0 autor tece reflexões em torno da seguinte questão: em que medida 0 conhecimento da trajetória dos realizadores das obras massivas e dos processos de fabricação destes produtos colabora na análise dos processos de consumo cultural e dos muitos modos de compreensão e interpretação dos sentidos ofertados, um dos muitos elementos que podem interferir nas práticas dos agentes, consumidores dos mass media nas sociedades contemporâneas. Os pontos aqui colocados advêm de pesquisa sobre os sentidos produzidos nas telenovelas brasileiras dos anos 90, exibidas após 0 Jornal Nacional, pela TV Globo.

\section{ABSTRACT \\ The author of this paper reflects upon the role played by one's knowledge about the producers and the processes responsible for media products in the analysis of cultural consumption and meanings generated by current mass media. \\ PALAVRAS-CHAVE (KEY WORDS) \\ - Telenovelas (Soap operas) \\ - Recepção (Reception) \\ - Realizadores (Producers)}

Maria Carmem Jacob de Souza ${ }^{1}$ UFBA
No INÍCIO DOS ANOS 90, pesquisadores do campo científico brasileiro que investigavam o fenômeno da recepção tinham como importante ponto de partida as proposições de Jesús-Martin Barbero que anunciavam as mediações, ${ }^{2}$ ou melhor, as interações, entre o espaço de produção e de recepção como caminho analítico necessário para examinar o fenômeno. Localizou três planos de análise articulados entre si: 1) a conformação e produção do produto, contemplando as relações entre as características econômicas da produção e distribuição e as dinâmicas institucionais e profissionais que regulam o funcionamento do campo cultural; 2) os relatos particulares do produto analisado; 3) as formas de apropriação que diversos grupos sociais e cultuais fazem das obras analisadas. Seguindo a trilha dos pesquisadores aglutinados na denominação ampla de Estudos Culturais, em especial na vertente formulada a partir de Stuart Hall, Barbero indicou, no primeiro plano de análise, o estudo das ideologias profissionais e as rotinas de operação, sem descurar das regras de funcionamento da empresa, da concorrência que rege o campo da produção e das estratégias de comercialização do produto. Dimensões que interessam sobremaneira nesse artigo.

Um dos fóruns de debate sobre a metodolgia proposta pelo autor ocorreu na primeira metade dos anos 90 no GT Mídia e Recepção da COMPÓS. Um dos assuntos debatidos remetia justamente a esse tripé que orientava o estudo: de que modo poderia um investigador 
solitário, vivendo condições precárias de trabalho, conseguir dar conta de tantas dimensões, muitas delas fora de sua área de formação. Analisar os produtos, analisar os processos de produção e circulação sem descurar das dimensões nacionais do fenômeno como exigência para os estudos de recepção parecia para muitos uma empreitada coletiva. Característica que poderia explicar, em parte, os estudos existentes que ora se debruçavam sobre a dinâmica da produção, ora sobre a análise de produtos ou análise da recepção propriamente dita, seja prometendo as articulações, seja as desenvolvendo de modo bastante incipiente, privilegiando a dimensão que o pesquisador tinha maior familiaridade e maior correspondência com suas áreas de formação. Muitos anos se passaram e várias experiências se desenvolveram ${ }^{3}$ inseminadas por Barbero e pelos representantes dos Estudos Culturais. Muitas críticas foram levantadas e novas perspectivas lançadas.

De qualquer modo, pode-se dizer que ainda se observa uma vertente nos estudos de recepção que busca estabelecer as relações entre o fenômeno da recepção dos produtos massivos e os processos de fabricação, circulação e análise das obras. Como decorrência, ampliou-se o número de estudos voltados ao processo de produção, sem contudo, parece, redundar em efetiva área de interesse daqueles que abordam o fenômeno da recepção. Acredita-se da importância de um estudo avaliativo das metodologias utilizadas nas pesquisas brasileiras para dar conta dos aspectos que envolvem a referida produção, verificando as articulações efetivadas com as outras dimensões que contemplam as premissas postas por Barbero e outros, para quem sabe até mesmo por em xeque a própria premissa.

De qualquer modo, digressões à parte, o que move esse texto é a necessidade de incitar um debate sobre um dos níveis considerados no plano da produção - o lugar que os profissionais que elaboram os produtos ocupam nesse processo.

Um dos autores que têm servido de referência para os estudos dedicados ao plano da produção, como é comumente chamado, tem sido Pierre Bourdieu, em especial os conceitos de campo e habitus que desenvolveu. Nas pesquisas realizadas $^{4}$ sobre telenovelas por nossa equipe, desde 1992, ocorreu uma aproximação mais estreita com as proposições do referido autor que permitiu a formulação de indicadores básicos para se analisar a dimensão da fabricação e circulação do produto, inter-relacionado-as com o processo de elaboração da própria obra e do papel dos realizadores na produção dos sentidos ofertados. Experiência analítica que gerou uma série de formulações teóricometodológicas. Parte delas será aqui exposta com o objetivo de estimular uma avaliação crítica do processo e a geração de questões que possam, quem sabe, aprimorar as estratégias metodológicas das investigações que se voltam para o fenômeno da recepção, partindo da necessidade de aferir de modo articulado os processos de fabricação, circulação, consumo e análise das obras.

\section{Obras e processos particulares de formulação}

Quando o fenômeno da recepção dos sentidos mediáticos é capturado pelo nosso olhar, uma das primeiras características observadas diz respeito aos produtos que são consumidos e que ocupam lugares expressivos na constituição dos imaginários, valores e práticas dos consumidores. No caso da televisão, por exemplo, eles são vários, com alguns deles apresentando características semelhantes, deixando a primeira impressão de ser tudo, no fundo, a mesma coisa, mas o olhar atento mostra que guardam peculiaridades em função da empresa que os produz, da importância econômica, do nível 
da audiência, da história particular de elaboração, das estratégias discursivas implementadas, da experiência profissional dos realizadores envolvidos e tantas outras.

Nessa medida, existem aspectos gerais do processo de formulação do produto ou obras culturais que devem ser relacionados e pensados a partir das peculiaridades que apresentam. No caso específico deste texto, as reflexões aqui presentes têm sua origem nos estudos sobre telenovelas.

Um outro ponto, nem sempre contemplado pelo olhar analítico, referese aos agentes que participam da elaboração das obras, os responsáveis pelos sentidos ofertados. Não se está aqui, com tal afirmação, transformando realizadores empregados pelas empresas do entretenimento em agentes portadores de ampla autonomia num processo fabril de elaboração das obras, mas se está pontuando que as posições e as práticas que desenvolvem trazem marcas maiores ou menores nesses produtos, e que são contratados pelas empresas em função, inclusive, das habilidades de imprimirem essas marcas, algumas delas irão, até mesmo, conformar a médio e longo prazos as griffes ou padrões gerais das empresas. Acredita-se, até, que se deva privilegiar o olhar sobre as rotinas de trabalho, nas habilidades e nos sistemas de percepção e apreciação desses agentes, fazendo-os funcionar como pontas de rede, vetores analíticos, feixes rizomáticos para o exame relacional do processo da fabricação do produto no sistema mais amplo que congrega os aspectos econômicos, políticos, ideológicos, culturais e estéticos de sua feitura, pois são estes agentes uns dos elos fundamentais entre o processo da produção, da circulação e da confecção da própria obra, dos sentidos apresentados aos consumidores.

Por fim, não se está aqui também transformando a análise das trajetórias destes agentes como ponto de partida e chegada suficientes para análise das obras ou de qualquer outra instância dos processos que constituem o fenômeno da recepção. Apenas se chama a atenção para a hipótese de que o exame dos processos de trabalho traz importantes questões e elementos que permitem garantir a dimensão relacional da investigação do fenômeno.

As proposições de Pierre Bourdieu parecem pertinentes para auxiliar na análise dessas relações, permitindo a construção de uma metodologia que explore os agentes envolvidos como uma chave-mestra do estudo. Para muitos a escolha desse autor é inadequada, já que as investigações em que se deteve priorizavam o campo de obras que expressava uma maior autonomização, como é o caso da literatura francesa do século dezenove. Mais do que isso, sua atenção aos media e aos produtos mais vinculados ao mercado sugere um equívoco, pois ele não aprofundou estudos de produtos massivos, ficando muitas vezes numa posição de defesa da maior autonomia dos campos da produção cultural contra os poderes devastadores do mercado e do mundo dos meios de comunicação.

Todavia, não se deve desconsiderar as contribuições mais expressivas que as proposições do referido autor podem oferecer, especialmente no que diz respeito às relações entre as práticas dos agentes e as lutas em prol do reconhecimento e da consagração estabelecidas nos campos das obras culturais, aos dispositivos de constituição das diferenças e das posições. Esse tema remete às condições de trabalho e às concepções de arte e não-arte; às funções políticas, sociais, culturais dos realizadores mais ou menos próximos da indústria da cultura. Relaciona-se às escolhas dos modos de narrar e representar que realizadores fazem a partir dos espaços de possíveis estético, ideológico, artístico, político que circulam, ou seja, aos sentidos circulantes na sociedade que no caso das telenovelas 
brasileiras de um determinado horário podem trazer à tona desde um debate com posições menos preconceituosas sobre o homossexualismo até a uma publicização de expressivos e polêmicos movimentos sociais, ensaiando o fortalecimento de posições mais à esquerda no espectro político sobre o tema abordado.

Assim sendo, ou melhor, crendo ainda que Bourdieu tem algo a dizer sobre os embates metodológicos que interessam a determinadas vertentes dos estudos de recepção, retomo uma de suas proposições, aquela que ajuda a investigar as relações entre os realizadores e a produção de sentidos em suas obras.

Pontos de vista de realizadores e a ciência das obras

Contrário à ideologia carismática do criador, seja em que campo da produção cultural for, Bourdieu supõe que $o$ ato ou a experiência de produção de obras culturais é a expressão de um ponto de vista, ou seja, uma tomada de posição, uma escolha em que o referido produtor deve ser encarado como aquele que "pôde ocupar ou, em certos casos, produzir as posições já feitas ou por fazer oferecidas por um estado determinado do campo"s.

A ciência das obras que Bourdieu propõe envolve um método de análise para examinar o referido ponto de vista do realizador. Define o exercício de três operações articuladas entre si: a primeira examina historicamente a posição do campo analisado no campo do poder, a segunda analisa a estrutura interna do campo e a terceira investiga a gênese dos habitus dos ocupantes dessas posições, compreendidas como sistemas de disposições construídos no desenrolar da trajetória social, ou seja, das posições ocupadas pelos indivíduos ou grupos observados em estados sucessivos do campo. Bourdieu não precisou uma ordem de procedimentos, já que trabalhava com um campo particular já constituído analiticamente, o campo literário. Todavia, considera-se que uma ordem seqüencial se impõe. Deve-se em primeiro lugar construir o campo da produção cultural relacionado às obras que se pretende analisar, só depois é possível desvendar um dos vetores de observação que se refere ao segundo momento do método, ou seja, a posição deste campo examinado no campo do poder, e por fim, o terceiro momento, o estudo da trajetória social dos principais produtores, que implica a análise das disposições, dos estados do campo, das posições e das tomadas de posição representadas nas obras que produziram, nos grupos que participaram, nas instituições com as quais se relacionaram ${ }^{6}$.

A construção de um campo supõe identificar e examinar um "universo que obedece às suas próprias leis de funcionamento e de transformação, isto é, a estrutura das relações objetivas entre as posições que indivíduos ou grupos nele ocupam, colocados em situação de concorrência pela legitimidade ${ }^{7 "}$.

A noção de campo presume um modo de pensar relacional do espaço social dos produtores - o microcosmo social no qual se produzem as obras culturais. Neste, a lógica interna dos objetos culturais, sua estrutura de linguagem, relaciona-se com as relações objetivas entre os agentes ou instituições que os elaboram. Isto porque se admite que é a partir das relações de força específicas e de lutas, que "têm por objetivo conservá-las ou transformá-las, que se engendram as estratégias dos produtores, a forma de arte que defendem, as alianças que estabelecem, as escolas que fundam ${ }^{8}$.

Ao analisar o campo literário francês, salientou que a oposição entre a dimensão desinteressada e pura do fazer artístico e a dimensão comercial estruturariam o campo da produção cultural e artística como um todo. O campo artístico, pensado através da idéia de subcampos correspondentes a cada um dos gêneros que o constituem, 
criados em função das particularidades das obras, dos objetos de disputa, dos públicos e de sistemas de consagração. Os subcampos manteriam entre si uma outra oposição, denominada de secundária, ortogonal à precedente, referente à qualidade das obras e à composição social do público. Examinar o subcampo da telenovela, por exemplo, significa então considerar feixes de oposição que o estruturam, em especial, as dimensões artística e desinteressada em tensão com a dimensão comercial, associadas com as características das obras e do público ${ }^{9}$. Por fim, seria importante salientar que os limites e a autonomia relativa dos campos são um produto histórico, cujas fronteiras não podem ser determinadas a priori, apenas através da investigação empírica ${ }^{10}$.

No caso específico das pesquisas sobre telenovelas que servem de lastro para este texto, foi necessário compor o campo da telenovela a partir da recomposição da história da formação de suas obras e seus realizadores, com a pretensão de cartografar a importância e o papel de cada um dos agentes e instituições envolvida. Buscou-se descortinar de que maneira as lógicas de outras práticas, como a econômica, a política e a artística, foram interferindo na constituição da telenovela e em qual momento uma certa autonomia se constituiu, enquanto expressão de lógicas particulares que regem a criação desse gênero ficcional. Essa abordagem histórica garantiu a identificação do que Bourdieu chamou de estados do campo, ou seja, marcos temporais que caracterizam um conjunto de condições particulares de exercício de determinadas formas de conceber e produzir as telenovelas.

A lógica particular do campo da telenovela surgiu assim a partir do exame da rede de relações objetivas entre as posições dos agentes, as suas disposições (habitus) e as escolhas estéticas, políticas e culturais que faziam acerca do que fosse uma telenovela. Na observação dessa rede ressaltaram os princípios geradores das diferenças e pontos de enlace que fundamentavam a referida lógica do campo.

Para identificar as posições dos agentes, explicita Bourdieu, é preciso identificar, de início, a histórica forma de distribuição dos capitais no campo, classificando-os em função da importância e do peso que teriam, para depois identificar as posições dos agentes que expressam os tipos e o volume dos capitais que possuem. Os capitais são os recursos possuídos pelos agentes que os diferenciam dos demais. Os recursos básicos seriam os econômicos, os culturais, o social (adquirido das redes de relações) e o simbólico (a autoridade e o reconhecimento). A idéia de campo específico de uma obra, como a telenovela, supunha também que, a partir das particularidades do espaço de produção da referida obra, ocorreria uma diferenciação de certos capitais específicos. Possuí-los significaria um importante diferencial de poder aos seus portadores.

O uso da noção de campo exige que se considere os processos de produção, reprodução, distribuição e consumo dos produtos e práticas a ele associados. Uma exigência de difícil realização, principalmente quando se lida com poucos estudos já efetuados sobre as obras escolhidas. De qualquer modo, pensase que por mais provisória e frágil tenha sido a conformação do campo, a lógica relacional que a anima sustenta as análises e os resultados alcançados, sabendose da precariedade que os caracteriza quando não foi possível formular com precisão o campo ou subcampo das obras investigadas.

Ao constituir o campo, identifica-se agentes e instituições formuladores de princípios que definem tanto os produtores e as obras quanto os sistemas de avaliação e reconhecimento de realizadores e suas práticas e produções. Deve-se caracterizar também o público consumidor e as instâncias de consagração e reprodução. As referidas instâncias, segundo Bourdieu, 
são necessárias para a recepção, na medida em que asseguram a existência e a formação dos consumidores e dos agentes capazes de reproduzir e renovar o consumo das obras. Quer dizer, elas exercem as funções de reproduzir os sistemas de apreciação e percepção das obras. Neste caso, salienta-se o papel cumprido pelos sistemas de ensino de caráter genérico e específico (das escolas do ensino fundamental aos conservatórios de música, por exemplo). Em suma, são instâncias que conformam sistemas particulares de diferenciação de produtores, consumidores e obras, ao mesmo tempo que garantem a conformação de cada um deles. Não se pode esquecer que, quando o fazem, se tem como pano de fundo as duas lógicas econômicas em tensão no campo, trafegando num espectro limitado ora pela adesão total às regras do mercado e a lucratividade que lhe é peculiar, ora pela insubordinação a essas mesmas regras.

Os museus, por exemplo, são instâncias clássicas que têm como função conservar os bens simbólicos legados pelos produtores, em especial os consagrados. No caso da telenovela vale lembrar o papel cumprido pelo Museu da Imagem e do Som, tanto no Rio de Janeiro quanto em São Paulo, na gestão de um acervo de imagens e documentos sobre telenovelas, assim como o papel que o Centro de Documentação da TV Globo tem cumprido, favorecendo o acesso das escolas e universidades ao seu acervo, além de utilizá-lo na formação de seus realizadores e como material para suas produções. Núcleos de pesquisa nas universidades também cumprem essa função. Um dos mais destacados tem sido o núcleo de telenovelas da ECA/USP.

O sistema de ensino genérico, a outra importante instância indicada por Bourdieu, exerce um importante papel na formulação dos sistemas de apreciação de obras e práticas, sendo uma das bases dos famosos critérios de cumplicidade necessários entre os produtores de obras massivas e seu público. As diferenças que o sistema gera no acesso ao capital cultural interferem ainda no acesso aos bens simbólicos e nas diversas apropriações e usos dos meios massivos. Os sistemas de formação específicos são aventados pelo autor como principais responsáveis pela conformação dos habitus secundários fundadores do ethos de realizador. No caso das telenovelas, tem-se desde a formação que ocorre a partir da própria experiência de trabalho, principalmente no início da sua história, quanto os espaços contemporâneos de formação de atores (o Tablado e o Centro de Artes de Laranjeiras - CAL, no Rio de Janeiro, por exemplo, do mesmo modo que as faculdades de teatro e cinema).

Um dos indicadores da hierarquização é a qualidade social e cultural do público, associada ao capital simbólico que assegura aos produtores seu reconhecimento e valor de consagração. Nessas situações, uma telenovela hoje, que tem um público mais acentuado situado nas camadas $C$ e $D$, tende a ter um reconhecimento mais frágil, ou quase nenhum, diante de um produto massivo voltado para um público consumidor das camadas A e B, como deve ser o caso do recente Normais, produzido pelo núcleo de Guel Arraes, TV Globo ${ }^{11}$.

Um outro refere-se à hipótese de Bourdieu de que os produtores distinguemse entre si a partir também do tipo de sucesso que fazem (associado ao público e as instâncias específicas de consagração). Por exemplo: "Os autores que chegam a conseguir os sucessos mundanos e a consagração burguesa (a academia, especialmente) distinguem-se tanto por sua origem social e sua trajetória quanto por seu estilo de vida e suas afinidades literárias daqueles que estão condenados aos sucessos ditos populares, tais como os autores de romances rurais, de vaudevilles ${ }^{12 "}$. Esta suposição incita, entre muitos procedimentos, a identificação dos aspectos que são apontados pelos 
próprios realizadores de telenovelas como certificados de sucessos que podem transcender ou não os índices de audiência ou o número de cartas recebidas, isto é, extrair os aspectos destacados pelos próprios realizadores das obras analisadas e de áreas afins que afirmem, demonstrem o reconhecimento de seus valores enquanto realizadores ${ }^{13}$, seja pelos próprios pares, seja pelo público telespectador. Importa ter o cuidado de associar esses certificados com as instâncias que têm o poder de aferir o reconhecimento, sem esquecer de relacioná-los com a origem social, trajetória, preferências e estilos de vida dos realizadores consagrados.

Uma outra premissa: o grau de autonomia do campo e subcampo examinados interfere na conformação desses certificados e nas instâncias que o legitimam e constroem ${ }^{14}$. Quanto maior o grau de autonomia, maior a tendência em se obter uma vantajosa margem de possibilidades para que os próprios realizadores instalem seus parâmetros de avaliação e reconhecimento, que podem ir da academia à vanguarda mais revolucionária.

O grau de autonomia do campo "varia consideravelmente segundo as épocas e segundo as tradições nacionais, sendo proporcional ao capital simbólico acumulado no decorrer do tempo pela ação das gerações sucessivas. Em nome desse capital coletivo os produtores culturais sentem-se no direito e no dever de ignorar as solicitações ou as exigências dos poderes temporais, ou até de as combater invocando contra elas seus princípios e suas normas próprias ${ }^{15}$ ". 0 campo da telenovela, um produto massivo que supõe um pequeno poder de refração diante das forças econômicas e políticas, tem mostrado, contudo, no caso brasileiro, um capital simbólico historicamente incorporado aos seus realizadores, a ponto de muitos conseguirem de fato imprimir experiências inovadoras e de significativo reconhecimento no campo artístico. Fenômeno que, mais uma vez, exige do analista a criatividade necessária para poder identificar e situar na história particular do campo os elementos que vêm compondo os certificados de bom escritor e bom diretor, por exemplo, tanto quanto as instâncias, indivíduos e grupos que têm tornado isso possível.

\section{Estabelecer as conexões entre as instâncias de reconhecimento} e consagração com o processo de autonomização dos campos conduz ao segundo momento do método da ciência das obras proposto por Bourdieu, isto é, posicionar o campo investigado no campo do poder ou analisar as relações de dominação presentes no campo estudado, tendo em vista que elas representam de algum modo o "efeito indireto de um conjunto complexo de ações que se engendram na rede cruzada de limitações que cada um dos dominantes (...) sofre de parte de todos os outros ${ }^{16 "}$, e por conseguinte, dos efeitos das posições dominantes de agentes ou instituições de um campo sobre os outros. O campo do poder, diz Bourdieu, não se confunde com o campo político, tendo sido cunhado para dar conta dos "efeitos estruturais" presentes em campos particulares, vistos como tal, porque dizem respeito à posição do campo analisado no espaço social mais amplo, ou seja, um conceito que objetiva evitar a compreensão das relações de dominação presentes num campo particular a partir apenas das práticas, representações e posições de indivíduos e grupos do referido campo. Para ser mais claro, um campo específico sofre, segundo o autor, de efeitos que advêm do campo do poder, ou do "espaço das relações de força entre agentes ou instituições que têm em comum possuir o capital necessário para ocupar posições dominantes nos diferentes campos (econômico ou cultural, especialmente) ${ }^{17 "}$. O que essa afirmação inspira é a busca de um modo de identificar por onde andam no espaço social mais amplo "as lutas pelos detentores de poderes (ou de espécies de 
capital) diferentes ${ }^{18 "}$ e de que modo tais lutas interferem na dinâmica particular de funcionamento dos campos, em especial os de produção cultural e os campos das obras analisadas.

Retomando novamente o autor, o "campo do poder é o espaço de relações de força entre os diferentes tipos de capital ou entre os agentes suficientemente providos de um dos diferentes tipos de capital para poderem dominar o campo correspondente e cujas lutas se intensificam sempre que o valor relativo dos diferentes tipos de capital é posto em questão (por exemplo, a 'taxa de câmbio' entre o capital cultural e o capital econômico) ${ }^{19}$ ". Nessa medida, uma das principais lutas presentes no campo do poder é pela conservação ou transformação dessas taxas de câmbio, que não são nada mais que a quantidade e o tipo de capital específico necessários para se ocupar posições dominantes no interior dos campos respectivos. Ater-se a essas lutas é dedicar-se à observação da produção, distribuição e sistemas de aquisição dos dois principais capitais específicos em disputa no espaço social e nos campos, bases para constituição dos princípios de diferenciação característicos das sociedades examinadas: ou seja, especialmente os capitais econômico e cultural.

O que essa operação analítica incita na análise da questão do ponto de vista dos realizadores e da análise de suas obras? Em primeiro lugar, o exame detalhado de práticas e representações de indivíduos, grupos e instituições dos campos de produção cultural diante do mundo econômico. Urge observar, seguindo essa trilha, de que modo se manifesta a suposta tensão permanente entre uma lógica econômica e uma economia carismática baseada no desinteresse econômico associado à intenção estética que proporcionaria um critério de apreciação mais autêntico e "puro" das obras e autores. Observar, por exemplo, a presença dessa tensão nas relações entre os artistas, escritores, realizadores em geral e os indivíduos, grupos e instituições responsáveis pela produção e difusão das obras, como editores, produtores (área do cinema, da televisão, do teatro), e tantos outros que cumprem essas funções no campo enfocado. Estes últimos seriam para Bourdieu aqueles que reúnem "disposições econômicas que, em certos setores do campo, são totalmente estranhas aos produtores, e disposições intelectuais próximas das dos produtores $^{20}$, dos quais podem explorar 0 trabalho apenas na medida em que sabem apreciá-lo e valorizá-lo21". Em segundo lugar, a operação analítica em xeque exige a identificação e o exame dos efeitos dos outros campos sobre o campo analisado, em especial daqueles que interferem mais diretamente na sua dinâmica particular, ou seja, o que ele denominou de "campos englobantes", ou seja, preferencialmente o campo econômico e o campo político, ou aqueles que influenciam no campo analisado os processos de construção dos seus princípios de hierarquização. Novamente, chega-se ao problema do grau de autonomia do campo examinado, em que medida o princípio de hierarquização externa estaria subordinado ao princípio de hierarquização interna, sem desconsiderar a relação deste problema com a suposta tensão permanente nos campos da produção cultural entre uma lógica econômica e uma economia carismática.

"Segundo o princípio de hierarquização externa, que está em vigor nas regiões temporalmente dominantes do campo do poder (e também no campo econômico), ou seja, segundo o critério do êxito temporal medido por índices de sucesso comercial (tais como a tiragem dos livros, o número de representações das peças de teatro, os cargos, etc.), a primazia cabe aos artistas (etc.) conhecidos e reconhecidos pelo 'grande público'. O princípio de hierarquização interna, 
isto é, o grau de consagração específica, favorece os artistas (etc.) conhecidos e reconhecidos por seus pares e unicamente por eles (pelo menos na fase inicial de seu trabalho) e que devem, pelo menos negativamente, seu prestígio ao fato de que não concedem nada à demanda do "grande público"22.

Essas afirmações de Bourdieu denunciam a sua exacerbada ênfase na análise dos subcampos de produção restrita, no qual o grau de autonomia tende a ser muito maior que os de grande produção, sugerindo uma tendência do autor de reconhecer a existência de ambos os princípios de hierarquização nos subcampos regidos pela lógica do mercado e pelas pressões do grande público, sem explorar, nestes casos, os dispositivos de análise de tais dimensões ${ }^{23}$.

O terceiro momento do método, atinente ao estudo da trajetória social dos produtores, implica a construção da biografia dos realizadores pautada na reconstituição

"da série de posições sucessivas ocupadas por um mesmo agente ou por um mesmo grupo de agentes em espaços sucessivos (...). é com relação aos estados correspondentes da estrutura do campo que se determinam em cada momento o sentido e o valor social dos acontecimentos biográficos, entendidos como colocações e deslocamentos nesse espaço ou, mais precisamente, nos estados sucessivos da estrutura da distribuição das diferentes espécies de capital que estão em jogo no campo, capital econômico e capital simbólico como capital específico de consagração ${ }^{24 " .}$

A construção da lógica particular do campo das obras pressupõe o exame da rede de relações objetivas entre as posições dos agentes, as suas disposições (habitus) e as escolhas estéticas, políticas e culturais que fazem sobre as obras. A observação dessa rede permite levantar princípios geradores das diferenças e pontos de enlace que fundamentam a referida lógica do campo.

As posições que os agentes ocupam no campo relacionam-se à história dos agentes, ao "senso prático que os caracteriza", ao modo de agirem. Esse senso prático ou habitus seria, para Bourdieu, uma disposição inconsciente, fruto das instituições e grupos socializadores da história do agente, que teriam viabilizado a interiorização histórica de uma série de sistemas de apreciação e classificação orientadores das suas ações. Os habitus seriam a expressão dessas relações entre a história das posições ocupadas pelos agentes e dos capitais que acumulam, ambos formadores do senso prático que orientam suas práticas.

Uma das estratégias usadas para flagrar as relações entre as posições, os habitus e as escolhas dos agentes é a construção das trajetórias dos realizadores, em especial os consagrados no campo. Elas descrevem, por exemplo, a série de posições ocupadas pelo mesmo escritor de telenovelas, em estados sucessivos do campo, a partir do estar escrevendo tal ou qual telenovela de determinado horário, em tal ou qual emissora, de ter participado (ou estar participando) em tal ou qual grupo etc, ${ }^{24}$.

A noção de trajetória busca romper com a idéia de que as obras são o produto das virtudes miraculosas do gênio criador. Isso leva à análise das escolhas estéticas, narrativas, e tantas outras, a partir dos limites das posições que os realizadores ocupam na estrutura de um estado muito específico de um microcosmo artístico historicamente situado e datado. Isso significa que os acontecimentos biográficos dos realizadores - alocações e deslocamentos no espaço social - são analisados em função dos diferentes 
estados sucessivos da estrutura da distribuição dos diferentes tipos de capital que estão em jogo no campo, ou seja, do conjunto de relações objetivas que vinculariam os agentes investigados ao conjunto dos outros agentes e ao espaço de possíveis demarcadores das escolhas das representações por eles efetuadas.

Para melhor compreender as escolhas que os agentes fazem recorrese à noção do espaço de possíveis ou do campo de possibilidades estratégicas que tende a orientá-los, "definindo o universo de problemas, de referências, de marcas intelectuais (freqüentemente constituídas pelos nomes de personagensguia) de conceitos em "ismo", em resumo, todo um sistema de coordenadas que é preciso ter em mente - o que não quer dizer na consciência - para entrar no jogo26". Quanto mais hábil for o agente diante desse sistema, mais profissional e não amador ele será considerado. "Esse espaço de possíveis é o que faz com que os produtores sejam ao mesmo tempo situados, datados, e relativamente autônomos em relação às determinações diretas dos ambientes econômico e social ${ }^{27 "}$

A análise das escolhas efetuadas por Barbosa e Carvalho diante dos modos possíveis de representar o popular em Renascer (TV Globo, 20h30, 1993), por exemplo, mostrou que elas estavam relacionadas às polêmicas específicas, ao universo de pontos em discussão de um determinado estado do campo da telenovela que definia se o bom diretor ou escritor de telenovelas devia representar o popular de forma realista e comprometida com posturas críticas diante das desigualdades sociais ${ }^{28}$. Essas considerações indicaram que as representações do popular escolhidas pelos agentes foram formuladas também a partir do que o popular significava no próprio campo. Nessa medida, se um dos pontos polêmicos derivava do caráter nacional ou não das telenovelas, esse era um aspecto do espaço de possíveis que mostrava a histórica relação entre a presença do popular nas telenovelas e as estratégias usadas para representar o ser brasileiro ${ }^{29}$.

A noção do espaço de possíveis ajuda sobremaneira a relacionar estilos, formatos das obras com o processo de criação das mesmas, sendo uma das portas de entrada para relacionar as dimensões externas ao texto às dimensões internas e próprias do texto (aspecto que não será aqui contemplado). Porém, para evitar que se concentre a atenção no aspecto artístico, individual, próprio dos realizadores, essas escolhas realizadas a partir do espaço de possíveis precisam ser relacionadas tanto às posições dos realizadores no campo quanto ao senso prático (habitus) que as orientam, pois esse é o cuidado básico que possibilitaria a observação das relações entre as estruturas sociais, as ações dos agentes singulares e os sentidos formulados.

Parafraseando o autor, somente depois de configurar o campo, as disputas que o constituem e os sistemas de consagração que o alimentam poder-seá analisar os realizadores e suas obras enquanto expressão das referidas relações históricas e particulares que constituem os universos de práticas que dialeticamente alimentam suas ações, seus sistemas de apreciação, disposições e representações. As estratégias metodológicas que os três momentos propostos pela ciência das obras instituem são a base para a explicitação de uma rede básica de procedimentos formulada para permitir identificar, observar, ordenar e analisar a dimensão sócio-histórica das práticas dos realizadores das obras e também das próprias obras, tornando possível, inclusive, identificar aqueles considerados autores das obras (quando isso é possível) a partir dos sistemas de consagração do campo analisado que qualificam e diferenciam realizadores, obras, grupos, instituições.

Tem-se clareza que tais elementos são importantes para investigar o fenômeno 
da recepção, apesar de por si só não serem suficientes. Em suma, que a reflexão aqui exposta possa incitar a avaliação crítica das estratégias analíticas e a formulação de questões a respeito de uma das muitas dimensões do fenômeno da recepção, aquela que diz respeito aos realizadores das obras culturais mediáticas, ao espaço social particular de produção, quer dizer, ao campo específico de relações de força, poder e de disputas que demarcariam uma rede de relações possível com os modos de narrar, representar e produzir sentidos .

\section{Notas}

1 Professora Adjunta da Faculdade de Comunicação da UFBA, doutora em Ciências Sociais PUC/SP e pesquisadora do CNPq. Este trabalho foi apresentado no GT mídia e recepção, no XI Encontro anual da Compós (UFRJ/RJ, 2002).

2 Uma noção deveras complexa, que não pode ser levianamente sintetizada desse modo. Porém, pode-se afirmar, que, grosso modo, as mediações sinalizam os lugares, as interfaces que constituem um fenômeno complexo como 0 da recepção, exigindo assim, por parte do investigador, a atenção voltada para a análise das relações dos elementos constitutivos desse fenômeno que teriam como pano de fundo as articulações das lógicas econômica e industrial com as demandas e os modos de ver dos diferentes grupos sociais examinados (Cf. Barbero, Jesús Martin.La telenovela em Colombia, Diálogos de la comunicacion, n.17, jun-1987, p.49).

3 Não se pode deixar de assinalar a importância das pesquisas realizadas pelo núcleo de telenovelas - ECA/USP, em particular aqueles sob a coordenação das pesquisadoras Vassalo, Fadul e Baccega.

4 A pesquisa atual, tecendo continuidade com as realizadas desde 1992, intitula-se "campo da telenovela e produção de sentidos: o lugar do diretor e escritor" e está sendo apoiada pelo CNPq e pelo Prodoc/ Ufba.

5 Bourdieu, Pierre. As regras da arte. São Paulo: Companhia das letras, 1996. p. 244.
6 Bourdieu não desconsidera a análise específica das obras e a dinâmica própria que 0 exame das obras impõe, apenas não tratei desse aspecto neste trabalho.

7 Bourdieu, Pierre, op.cit., p. 243.

8 Bourdieu, Pierre. Razões Práticas. Campinas: Papirus, 1996, p. 60.

9 C.f. Bourdieu, op.cit, p. 65.

10 Cf. idem, p. 43.

11 Bourdieu, Pierre. As regras da ... p. 248.

12 Bourdieu, Pierre.Op.cit.,p. 249.

13 Sente-se a necessidade de esclarecer que o termo realizadores diz respeito a todo e qualquer agente envolvido na elaboração da obra: do cameraman ao âncora do telejornal, do produtor executivo de um programa de auditório à apresentadora do programa, e assim vai. Lidar com um conjunto numeroso de profissionais implica conhecer a hierarquia interna desses grupos, os pormenores do trabalho coletivo desenvolvido, entre outros aspectos, para melhor definir os critérios de seleção dos realizadores que serão objeto de análise, assim como para melhor definir aqueles que possuem 0 maior quinhão de poder na definição do conteúdo e dos meios expressivos empregados na formulação da obra e dos sentidos ofertados ao público.

14 Bourdieu, Pierre.op.cit.,p. 250.

15 ibid.

16 Bourdieu, Pierre. Razoes Práticas..., p. 52.

17 Bourdieu, Pierre. As regras da..., p. 244.

18 ibid

19 Bourdieu, Pierre. Razões Práticas..., p. 52.

20 No caso da telenovela os casos de Bonifácio de Oliveira Sobrinho e de Daniel Filho merecem especial atenção.

21 Bourdieu, Pierre. As regras da..., p. 245. 
23 Uma reflexão ampliada sobre as críticas proferidas a Bourdieu, ver Canclini, Nestor. Culturas Híbridas. México: Grijaldo, 1989 e Shusterman, Richard. Vivendo a arte. São Paulo: Editoria 34. 1998.

24 Bourdieu, Pierre, op.cit. p. 292.

24 Cf. Bourdieu, Pierre. As razões práticas...p. 71.

26 Bourdieu, Pierre. Op.cit. p. 53.

27 Ibid.

28 Assim como tais posturas remetem ainda ao estilo melodramático presente nos romances folhetins franceses do século XIX ou no cinema americano. Cf. Romano, Maria Carmem. Campo da telenovela e representação do popular. Tese de doutorado. PUC/SP, 1999.

29 Indicações analíticas que supõem investigar as relações entre os pontos definidores de estilos e formas de expressão do popular e da realidade brasileira nas telenovelas com as polêmicas internas ao campo que estabelecem associações com as polêmicas sobre a mesma questão que estiverem sendo desenvolvidas em outros campos, como o cinematográfico, teatral e literário. Essas controvérsias traduzem, assim, um dos importantes elementos dos espaços de possíveis que permitem examinar as escolhas e modos de representar dos realizadores de telenovelas. 